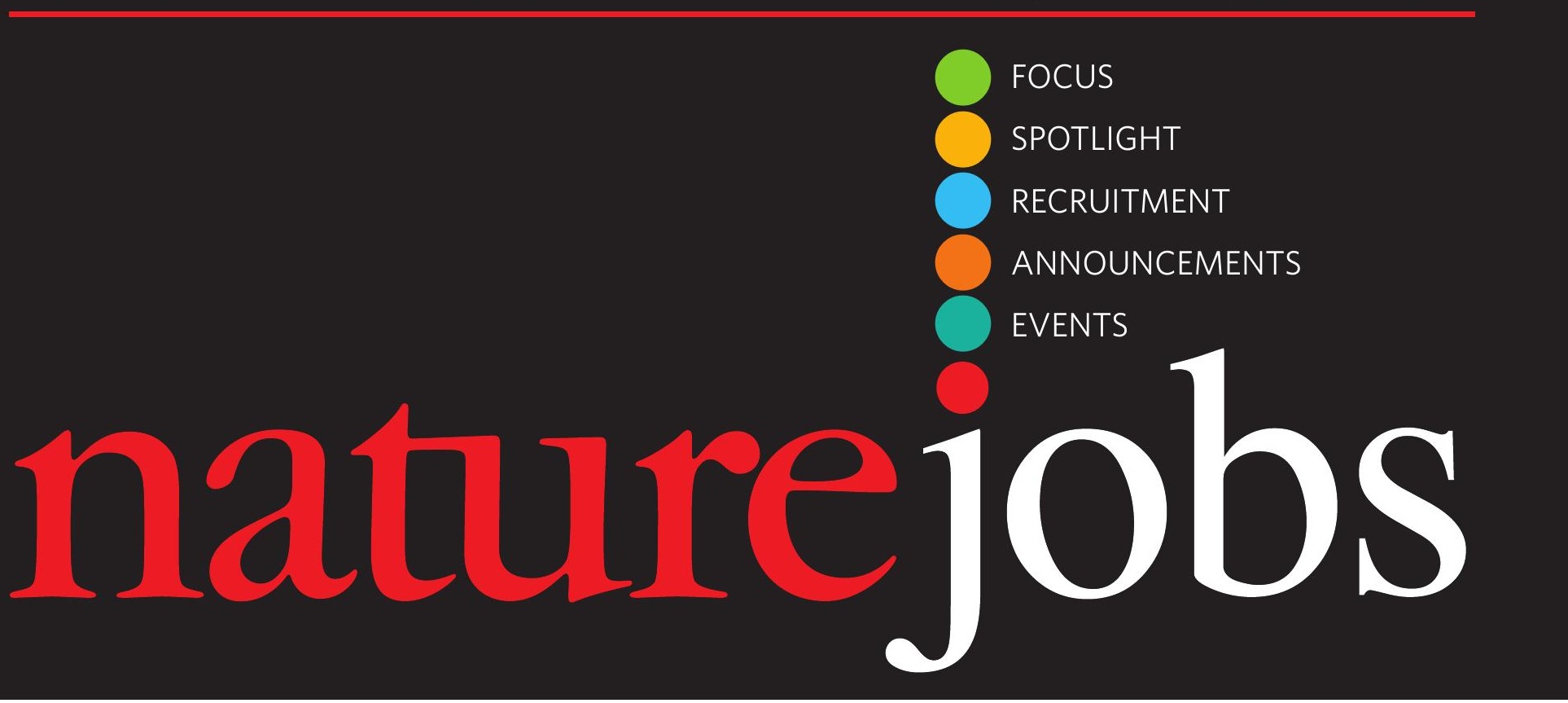

\title{
Same society, different rules
}

PhD students at the 80 Max Planck Institutes in Germany often feel torn between two masters. On the one hand, they fall directly under the jurisdiction of the director of their respective institute, which means that factors such as teaching loads and funding type vary from place to place. On the other hand, they are all overseen by the Max Planck Society, which funds each of the institutes and sets general policies.

To help them to navigate between these two centres of control - and to try to end pay and workload disparities between institutes - the PhD students joined forces a few years ago under the umbrella of PhDnet.

To illustrate their woes, the students this year did a survey, which produced some uncomfortable results. They found that it takes an average of 3.6 years for a Max Planck graduate student to secure a PhD, which is potentially problematic as the society provides funds for only three years. It also revealed that the students are getting funds from a wide range of sources: some rely on stipends, others on salaries, and some dip into their own resources. And the funding amounts and sources seem

CONTACTS

Publisher: Ben Crowe

Editor: Paul Smaglik

Assistant Editor: Corie Lok

European Head Office, London

The Macmillan Building, 4 Crinan Street London N1 9XW, UK

Tel: +44 (0) 2078434961

Fax: +44 (0) 2078434996

e-mail: naturejobs@nature.com

Naturejobs Sales Director:

Nevin Bayoumi (4978)

European Sales Manager:

Andy Douglas (4975)
Natureevents: Sille Opstrup (4994)

UK/RoW/Ireland/Italy:

Nils Moeller (4953)

Irene Viglia-Atton (4944)

Scandinavia/Spain/Portugal:

Evelina Rubio Håkansson (4973)

France/Switzerland/Belgium:

Amelie Pequignot (4974)

Germany/Austria/The Netherlands:

Reya Silao (4970)

Advertising Production Manager:

Billie Franklin

To send materials use London

address above.

Tel: +44 (0) 2078434814 to vary widely between Germans and non-Germans.

The students presented their results to Max Planck president Peter Gruss at their annual meeting in Göttingen last month. But after the meeting Gruss said that decisions on workloads, pay and funding types are best left to individual institute directors, which somewhat blunts the strength of PhDnet's collective bargaining.

So what will happen now? If Gruss is unable - or unwilling - to dictate such policies for the institutes, all he can do is pass on the students' data and leave it up to the directors whether or not to take action. The survey results might, of course, prove more useful to future students, who will be able to compare the institutes and apply to those that have a good track record of giving fair contracts and reasonable teaching loads.

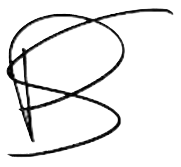

\section{Paul Smaglik, Naturejobs editor}

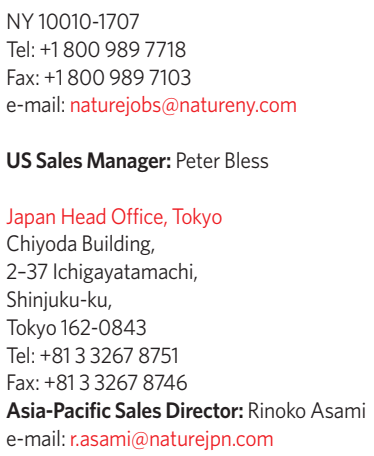

